\title{
Powdery Mildew Resistance in Wheat Cultivar Mv Hombár is Conferred by a New Gene, $\mathrm{PmHo}$
}

\author{
Judit Komáromi, Tünde Jankovics, Attila Fábián, Katalin Puskás, Zengyan Zhang, Miao Zhang, Hongjie Li, \\ Katalin Jäger, László Láng, and Gyula Vida
}

First, third, fourth, eighth, ninth, and tenth authors: Agricultural Institute, Centre for Agricultural Research, Hungarian Academy of Sciences (MTA), Brunszvik 2, H-2462 Martonvásár Hungary; second author: Plant Protection Institute, Centre for Agricultural Research, MTA, P.O. Box 102, H-1525 Budapest; fifth, sixth, and seventh authors: National Key Facility for Crop Gene Resources and Genetic Improvement, Institute of Crop Sciences, Chinese Academy of Agricultural Sciences, Zhongguancun South Street 12, Beijing 100081.

Accepted for publication 14 June 2016.

\begin{abstract}
Komáromi, J., Jankovics, T., Fábián, A., Puskás, K., Zhang, Z., Zhang, M., Li, H., Jäger, K., Láng, L., and Vida, G. 2016. Powdery mildew resistance in wheat cultivar Mv Hombár is conferred by a new gene, PmHo. Phytopathology 106:1326-1334.

A new powdery mildew resistance gene designated as PmHo was identified in 'Mv Hombár' winter wheat, bred in Martonvásár, Hungary. It has exhibited a high level of resistance over the last two decades. Genetic mapping of recombinant inbred lines derived from the cross 'Ukrainka' $/ \mathrm{Mv}$ Hombár located this gene on chromosome 2AL. The segregation ratio and consistent effect in all environments indicated that $\mathrm{PmHo}$ is a major

dominant powdery mildew resistance gene. The race-specific nature of resistance in Mv Hombár was shown by the emergence of a single virulent pathotype designated as 51-Ho. This pathotype was, to some extent, able to infect Mv Hombár, developing visible symptoms with sporulating colonies. Microscopic studies revealed that, in incompatible interactions, posthaustorial hypersensitivity reaction was the most prevalent but not exclusive plant defense response in Mv Hombár, and fungal growth was mostly arrested during haustorium formation or in the early stages of colony development. The delayed fungal development of the virulent pathotype 51-Ho may be explained by additional effects of other loci that were also involved in the powdery mildew resistance of Mv Hombár.
\end{abstract}

Wheat powdery mildew, caused by Blumeria graminis f. sp. tritici, is one of the most important diseases worldwide (Dean et al. 2012). The average yield loss due to this disease ranges from 5 to $8 \%$ and may exceed $35 \%$ in the case of severe infection in Europe (Cowger et al. 2012). Breeding for resistance is the most environmentally sound measure in disease control.

More than 70 formally designated major powdery mildew resistance genes $(\mathrm{Pm})$ have been cataloged thus far (McIntosh et al. 2014). The resistance conferred by these genes is race specific and, therefore, may lose effectiveness, particularly if used excessively on large areas (Bennett 1984; Brown and Hovmøller 2002). In Hungary, genotypes carrying major resistance genes Pm2, Pm3c, Pm4a, Pm5, Pm6, Pm17, and Pm8 (the most common gene) no longer confer effective control of powdery mildew in this region (Komáromi and Vida 2009). During the same field survey, however, resistance genes Pm3d, Pm3f, Pm4b, and $P m 5$ and the gene combination $P m 2+6$ conferred resistance. In addition, Pm21 conferred resistance to all isolates of $B$. graminis f. sp. tritici in both greenhouse tests and field trials (Komáromi et al. 2014). The effectiveness of Pm21 may be explained by the fact that no cultivars carrying this gene are currently cultivated in Hungary. Similarly, Pm3d is absent in local cultivars, although this gene was reported in several cultivars of European origin (McIntosh et al. 2016). The emergence of new pathotypes in pathogen populations and consequent loss of effectiveness of widely used major resistance genes (Brown and Hovmøller

Corresponding author: G. Vida; E-mail address: vida.gyula@agrar.mta.hu

*The $\boldsymbol{e}$-Xtra logo stands for "electronic extra" and indicates that one supplementary table is published online.

http://dx.doi.org/10.1094/PHYTO-03-16-0152-R

(C) 2016 The American Phytopathological Society
2002) means that there is an ongoing need to identify new genes or nonrace-specific quantitative trait loci (QTL) conferring more durable broad-spectrum resistance, and to utilize them in wheat breeding.

Plants generally have two main defense mechanisms, depending on the nature of plant-pathogen interactions: host resistance and nonhost resistance (Gill et al. 2015). Host resistance (Eichmann and Hückelhoven 2008; Hückelhoven and Panstruga 2011) is mainly controlled by single major resistance genes following the gene-for-gene concept (Flor 1971). Whereas nonhost resistance is usually more complicated due to the involvement of multiple pathways regulated by more genes, it is nonrace-specific and, thus, more durable (Niks and Marcel 2009; Schulze-Lefert and Panstruga 2011). These two types of resistance were repeatedly shown to share similar cellular response patterns at the microscopic level, involving, among other things, the formation of effective papillae (epidermal cell wall appositions) and the occurrence of cells showing hypersensitivity reaction (HR) after the development of haustoria (fungal feeding structures) (posthaustorial HR) inside the epidermal cells, followed by restricted fungal development (Hao et al. 2013; Thordal-Christensen 2003; Trujillo et al. 2004b). Moreover, similar cytological and biochemical mechanisms were involved in resistance responses conferred by major resistance genes and QTL in the interaction of tomato and its adapted powdery mildew fungus, Oidium neolycopersici $(\mathrm{Li}$ et al. 2012). Despite these similarities in plant-pathogen interactions, the frequency of penetration and, thus, the relevance of papillae and posthaustorial HR in resistance varies among different types of plant defense. Although HR was shown to play a role in nonhost powdery mildew resistance (Trujillo et al. 2004a), very low penetration frequencies accompanied by the predominance of effective papilla formation were shown in this type of resistance in some works (Cheng et al. 2015; Hückelhoven et al. 2001). Generally, inhibition of fungal development due to posthaustorial HR was associated with host resistance (Gill et al. 2015; Jørgensen 
1994). Therefore, microscopic studies on plant-pathogen interactions at a cellular level might contribute to the phenotypic characterization of novel resistance.

A high level of powdery mildew resistance has been repeatedly observed over the last two decades in 'Mv Hombár' winter wheat (bred in Martonvásár, Hungary; pedigree: 'Fleming'/'Mv Matador'), and has been expressed in greenhouse seedling tests and field experiments. However, the genetic background of this resistance has never been studied before. The aims of the present study were to (i) determine the chromosomal location of genetic factors associated with powdery mildew resistance in Mv Hombár using diversity arrays technology (DArT) and simple-sequence repeat (SSR) analysis of a recombinant inbred line (RIL) population and (ii) characterize the interaction between B. graminis f. sp. tritici and Mv Hombár at a microscopic level.

\section{MATERIALS AND METHODS}

Plant materials. For the genetic analysis of powdery mildew resistance in Mv Hombár, it was crossed with 'Ukrainka' winter wheat (bred in Odessa, Ukraine). Ukrainka has no known $P m$ genes, and is susceptible to the naturally occurring powdery mildew population in Hungary. $\mathrm{F}_{2}$ plants were evaluated for powdery mildew infection in the field, and 100 resistant and 100 susceptible individuals were selected to create a mapping population of 200 RIL. The two groups of RIL, representing resistant and susceptible progeny, were further selected for single-seed descent in $F_{3}$ and $F_{4}$. Afterward, the RIL were propagated without further selection in a single 2-m row and were then assessed for powdery mildew resistance.

For the segregation tests, susceptible Chinese wheat 'Han 4589' and 'Mingxian 169' were used in crosses with Mv Hombár. $F_{2: 3}$ populations were developed from the Mv Hombár/Han 4589 and Mingxian 169/Mv Hombár cross combinations.

Evaluation of powdery mildew infection and phenotypic analysis. In field experiments, the powdery mildew resistance of the RIL and parents was assessed in the Centre for Agricultural Research, the Hungarian Academy of Sciences (Martonvásár, Hungary) during three growing seasons (2012 to 2014) when the RIL were in $\mathrm{F}_{6}, \mathrm{~F}_{7}$, and $\mathrm{F}_{8}$ generations. The experiments were performed at two locations in a total of five environments. At location 1 , the RIL and parents were sown in one replication in single 2-m rows in all 3 years, with a row spacing of $0.4 \mathrm{~m}$. At location 2 , each genotype was sown in the years 2013 and 2014 in an experimental plot consisting of five 2-m rows for each genotype, with a row spacing of $0.15 \mathrm{~m}$. At location 2, one and two replications were sown in a randomized complete block experiment in 2013 and 2014, respectively. The sowing dates were optimal (middle 10 days of October) every year. All the experiments were bordered by plots of a highly susceptible winter wheat breeding line, MVMA/BIPE, to ensure the natural occurrence of powdery mildew inoculum.

Powdery mildew infection was evaluated at five scoring dates at 1-week intervals from early May until the middle of June. Two scoring methods were used in parallel: the 0-to-9 scale described by Saari and Prescott (1975), and the percentage of diseased leaf area. Areas under the disease progress curve (AUDPC) were calculated from these datasets. The Saari-Prescott data and the percentages of diseased leaf area recorded at the last scoring date and the two sets of AUDPC data represented the four datasets included in further analyses. Normality tests were carried out on the field and greenhouse data using Kolmogorov-Smirnov (Chakravarti et al. 1967) and Shapiro-Wilk (Shapiro and Wilk 1965) statistics. The Kruskal-Wallis test (Kruskal and Wallis 1952) was used to compare the RIL based on their powdery mildew resistance. Phenotypic datasets, consisting of the powdery mildew infection recorded at different locations in different years using different scoring methods, were compared in pairwise tests using the Mann-Whitney probe (Mann and Whitney 1947).

In the greenhouse experiments, the powdery mildew infection of the RIL and parents was evaluated at the seedling stage in
Martonvásár, Hungary in 2006 to 2008 and in 2010, when the RIL were in $\mathrm{F}_{3}, \mathrm{~F}_{4}$, and $\mathrm{F}_{5}$ generations. Two seedlings of each genotype were grown from seed in isolation in a greenhouse compartment at a temperature of $18^{\circ} \mathrm{C}$ under $14 \mathrm{~h}$ of natural and artificial illumination. Inoculation was carried out 10 days after sowing with a naturally occurring powdery mildew population, which was captured using susceptible trap plants of widely used winter wheat cultivars with different genetic backgrounds; namely, 'Bezostaya 1', 'Martonvásári 4', 'Martonvásári 22', 'Baranjka', 'Yubileynaya 50', 'Kavkaz', 'Maris Huntsman', 'Fatima 2', 'Martonvásári 15', 'Mv Pálma', 'Mv Emma', 'Mv Magdaléna', 'Mv Süveges', and 'Mv Magvas'. Infection types (IT) were recorded 8 days after inoculation on a 0 -to- 4 scale, where 0 represented an immune reaction without visible symptoms and 1 to 4 indicated highly resistant, moderately resistant, moderately susceptible, and highly susceptible responses, respectively. Genotypes with scores of 0 to 2 were considered resistant, while those with scores of 3 to 4 were considered susceptible.

Segregation tests were carried out in a greenhouse compartment at the Institute of Crop Science, CAAS, in Beijing by assessing the powdery mildew infection on $\mathrm{F}_{2}$ populations developed from the Mv Hombár/Han 4589 and Mingxian 169/Mv Hombár cross combinations. The $\mathrm{F}_{2}$ plants, $\mathrm{Mv}$ Hombár (resistant control), and Chancellor (susceptible control) were grown from seed in $15-\mathrm{cm}-$ diameter pots, with 25 plants in each pot, after which 25 seedlings of each of $179 \mathrm{~F}_{3}$ families, derived from the Mv Hombár/Han 4589 $\mathrm{F}_{2}$ plants tested above, were further tested to confirm the segregation. E20, a prevailing pathotype in the Beijing area, was used for inoculation. This pathotype was avirulent on Mv Hombár at both the seedling and adult plant stages but virulent on Han 4589 and Mingxian 169. The environmental conditions, inoculation methods, and evaluation of IT were similar to those described for seedling tests on RIL in Hungary. To compare observed data and expected segregation ratios, $\chi^{2}$ tests were used.

DNA extraction, SSR, and DArT analyses. Genomic DNA was extracted from leaf tissue collected from RIL seedlings in the $\mathrm{F}_{6}$ generation and parental cultivars using a Qiagen DNeasy Plant Mini Kit (Qiagen GmbH, Hilden, Germany) according to the manufacturer's instructions. The concentration of the DNA samples was measured using a spectrophotometer (NanoDrop ND-1000; NanoDrop Technologies Inc., Wilmington, DE), and was adjusted to $50 \mathrm{ng} / \mu \mathrm{l}$.

SSR amplification was performed as described by Röder et al. (1998), with some modifications. In total, 66 SSR markers were screened for polymorphism between the parental cultivars and 30 polymorphic markers (gwm2, gwm5, gwm44, gwm60, gwm71, gwm120, gwm135, gwm154, gwm155, gwm156, gwm165, gwm181, gwm190, gwm194, gwm233, gwm251, gwm272, gwm311, gwm314, gwm325, gwm332, gwm337, gwm415, gwm455, gwm469, gwm497, gwm609, gwm626, gwm635, and gwm666) were selected to analyze the RIL. Amplifications were carried out using combinations of infrared dye (IRD)-labeled forward primers and unlabeled reverse primers. For each polymerase chain reaction (PCR), the $10-\mu$ l total reaction volume consisted of $75 \mathrm{ng}$ of template DNA, $1 \mathrm{U}$ of Taq polymerase, $1 \times$ PCR buffer, $1.5 \mathrm{mM} \mathrm{MgCl} 2,0.2 \mathrm{mM}$ dNTP, $0.2 \mu \mathrm{M}$ unlabeled reverse primer, and $0.2 \mu \mathrm{M}$ IRD 700-labeled forward primer or $0.2 \mu \mathrm{M}$ IRD 800 -labeled forward primer. The PCR profiles were as follows: $94^{\circ} \mathrm{C}$ for $5 \mathrm{~min}$; followed by 30 cycles at $94^{\circ} \mathrm{C}$ for $1 \mathrm{~min}, 50$ to $60^{\circ} \mathrm{C}$ (depending on the specific primers) for $45 \mathrm{~s}$, and $72^{\circ} \mathrm{C}$ for $45 \mathrm{~s}$; followed by 8 cycles at $94^{\circ} \mathrm{C}$ for $1 \mathrm{~min}, 52^{\circ} \mathrm{C}$ for $45 \mathrm{~s}$, and $72^{\circ} \mathrm{C}$ for $45 \mathrm{~s}$; and a final extension at $72^{\circ} \mathrm{C}$ for $10 \mathrm{~min}$. Prior to gel electrophoresis, the PCR products were diluted $5 \times$ in formamide loading buffer (95\% formamide, $10 \mathrm{mM} \mathrm{EDTA} \mathrm{[pH} \mathrm{8.0],}$ and $0.1 \%$ fuchsin), then denatured for $5 \mathrm{~min}$ at $94^{\circ} \mathrm{C}$ and cooled on ice immediately. The products were separated in $6 \%$ denaturing polyacrylamide gel, and SSR data were collected automatically using a Li-Cor 4300 automated sequencer (Li-Cor Inc., Lincoln, NE).

In total, 180 DNA samples obtained from the RIL and parents were sent to Diversity Arrays Technology Pty Ltd. (Yarralumla, 
Australia) and genotyped with a custom-built wheat DArT array, version Wheat $P s t \mathrm{I}($ Taq $\mathrm{I})$, using 1,230 binomial dominant markers, as described by Akbari et al. (2006).

Linkage mapping. Linkage maps were constructed with the program JoinMap (version 4; van Ooijen, Wageningen, The Netherlands) using Haldane's mapping function. Of the 1,260 DArT and SSR markers, 825 were excluded from the analysis. The linkage groups were identified based on 435 SSR and DArT markers that showed a high level of reproducibility and polymorphism (expressed as the polymorphism information content value) and a low level of missing data, and exhibited a unique SSR or hybridization patterns. The locations of the SSR and DArT markers were determined based on the databases found at the GrainGenes (http:// wheat.pw.usda.gov/ggpages/SSRclub/GeneticPhysical/) and Triticarte (http://www.diversityarrays.com/) websites, respectively.

MapQTL (version 5; van Ooijen) was used for the QTL analysis. Phenotypic data obtained from the field trials were analyzed for each experimental location, year, and scoring method, as well as for the IT recorded in the seedling tests. The means and grand means of all the datasets were also analyzed. After performing interval mapping (IM), the significance of the detected QTL was estimated by permutation tests (at confidence levels of 99.9, 99, and 95\%). The multiple QTL model (MQM) procedure included all chromosomes with significant $(P<0.05)$ putative QTL obtained from IM. The QTL obtained with MQM were tested for significance $(P<0.001)$ with a global permutation test $(n=10,000)$. The confidence interval $(99.9 \%)$ of the QTL was estimated by bootstrapping with 10,000 samples.

Microscopic observations on plant-pathogen interactions. Light and confocal laser-scanning microscopy (CLSM) studies were performed to observe the stage of fungal growth when B. graminis f. sp. tritici was arrested in the leaves of Mv Hombár and the plant defense response. In addition to Mv Hombár, the following genotypes were included in the experiments: Ukrainka and 'Carstens V' winter wheat as susceptible controls; 'Nannong 02Y23' winter wheat, carrying Pm21 and found to be totally resistant both in field and greenhouse trials (Komáromi et al. 2014) to represent host resistance; and 'Orca' barley as a nonhost control. Twenty seedlings each of the five genotypes were grown from seed in four replications, each of which was separately isolated, in a greenhouse compartment under the conditions described above for the seedling tests. Three replications were inoculated 6 days after sowing using three different pathotypes propagated from single powdery mildew colonies, while one replication remained untreated and served as a negative control. Pathotypes were captured previously using susceptible trap plants of Yubileynaya 50, Mv Magdaléna, and Mv Süveges, and their virulence profiles were defined using a differential set of cultivars (Nover 1958), with modifications (Szunics and Szunics 1984). Pathotypes 76 and 51 were selected for inoculation because they have shown the highest frequency (approximately 70 to $90 \%$ ) in naturally occurring populations of $B$. graminis f. sp. tritici in Hungary in recent years. Within pathotype 51 , a recently emerged subpopulation (identified in this work and referred to as pathotype 51-Ho) that causes visible symptoms on Mv Hombár was also used for inoculation. The experiment was carried out twice. Samples were collected 8, 16, 24, $32,40,48,72,96$, and $168 \mathrm{~h}$ postinoculation (hpi). Two seedlings of each genotype were removed at each sampling date and were cut into segments approximately $5 \mathrm{~cm}$ in length.

The leaf segments were prepared for light microscopy by staining with a $1 \mathrm{mg} / \mathrm{ml}$ aqueous solution of 3,3'-diaminobenzidine (DAB) and aniline blue $(5 \mathrm{mg} / \mathrm{ml}$ in $0.07 \mathrm{M}$ sodium phosphate buffer, pH 9), as described by Hückelhoven et al. (1999). During light microscopy, the following features were studied: the formation of appressorial germ tubes; the penetration of epidermal cells; the haustorium formation inside the epidermal cells and the stage of haustorial development; colony formation involving hyphal branching and the appearance of further penetration sites; the emergence of conidiophores and the formation of mature conidia to monitor fungal development; and papillae formation, the accumulation of $\mathrm{H}_{2} \mathrm{O}_{2}$, and HR to explore plant defense responses (Thordal-Christensen et al. 1997).

In parallel, leaf segments were prepared for CLSM studies, as described by Jankovics et al. (2015), for infection with B. graminis f. sp. tritici ascospores. The CLSM studies focused on the penetration pegs, the formation and development of haustoria, the formation of papillae, and the HR. Aniline blue-stained samples were excited at either $405 \mathrm{~nm}$, as usual, or at $633 \mathrm{~nm}$, using sequential scanning mode. When excited at $405 \mathrm{~nm}$, autofluorescence from plant tissues and haustoria and fluorescence from callose structures were detected (Ellinger et al. 2013) (channel 1, shown in blue in CLSM micrographs). In the present study, a new detection method of aniline blue staining was introduced, as follows: when excited at $633 \mathrm{~nm}$, structures exhibiting blue color in visible light (fungal structures with the exception of haustoria; papillae and epidermal cells undergoing HR) yielded strong red fluorescence emission between 750 and $800 \mathrm{~nm}$ (channel 2, shown in red in CLSM micrographs). Series of confocal images were acquired with a Leica TCS SP8 confocal laser-scanning microscope (Leica Microsystems GmbH, Wetzlar, Germany). Three-dimensional reconstructions were obtained using Leica Application Suite Advanced Fluorescence software.

\section{RESULTS}

Phenotypic analysis. Normality tests on the field and greenhouse data revealed that the frequency distribution among the RIL was arbitrary. Kruskal-Wallis statistics confirmed significant between-genotype differences $(P<0.001)$ within each treatment. The Mann-Whitney test revealed no significant differences between years for the phenotypic data recorded at locations 1 and 2, except for the year 2013 at location 1, while the phenotypic data obtained at the two locations were similar in 2013 but differed in 2014.

Greenhouse tests revealed that RIL selected as susceptible in $\mathrm{F}_{2}$ were always susceptible at the seedling stage (IT 4). Among the RIL selected as resistant in $\mathrm{F}_{2}, 33,29,25$, and $38 \%$ were susceptible (IT 3 to 4 ) in 2006, 2007, 2008, and 2010, respectively.

Segregation tests showed that $\mathrm{F}_{1}$ plants of Mv Hombár/Han 4589 and Mingxian 169/Mv Hombár were resistant, indicating the dominance of resistance. The $\mathrm{F}_{2}$ population of Mingxian 169/Mv Hombár segregated into 79 resistant and 26 susceptible plants $\left(\chi^{2}{ }_{3: 1}=\right.$ $0.06, \mathrm{df}=1, P>0.25)$, fitting a $3: 1$ resistant/susceptible ratio. The $\mathrm{F}_{2}$ population of Mv Hombár/Han 4589 segregated into 253 resistant and 72 susceptible plants $\left(\chi_{3: 1}^{2}=1.404, \mathrm{df}=1, P>0.10\right)$, also fitting a 3:1 resistant/susceptible ratio. The $F_{3}$ families segregated into 45 homozygous resistant, 96 segregating, and 38 homozygous susceptible plants $\left(\chi^{2} 1: 2: 1=1.49, \mathrm{df}=1, P=0.25\right)$, fitting a $1: 2: 1$ homozygous resistant/segregating/homozygous susceptible ratio. Segregation in both the $F_{2}$ populations and $F_{3}$ progenies confirmed the monogenic inheritance of powdery mildew resistance in $\mathrm{Mv}$ Hombár.

Genetic mapping and QTL analysis. In total, 180 genotypes, including 89 resistant and 89 susceptible RIL as well as the parental cultivars, were finally subjected to DArT and SSR analysis. Based on 435 DArT and SSR markers, 46 linkage groups were identified spanning all chromosomes. MQM-based QTL analysis using separate powdery mildew infection datasets from the individual field environments showed the presence of four QTL associated with powdery mildew resistance. The four QTL were located on chromosomes 2AL (flanking markers $X w P t-665330$ and $X w P t$ 3114), 1A (flanking markers Xgwm497 and XwPt-2497), 2B (flanking markers XwPt-8460 and XwPt-2293), and 2D (flanking markers $X w P t-4691$ and $X w P t-665317)$ (Fig. 1). No consistent effect on resistance was found in the case of the QTL located on chromosomes 1A, 2B, and 2D. The QTL identified on chromosome 1A contributed to field resistance in the years 2012 and 2013, while the QTL detected on chromosomes 2B and 2D were involved in field resistance in 2014. 
The QTL located on chromosome 2AL was detected in all environments for the four phenotypic datasets recorded in the field and showed a major effect on powdery mildew resistance, indicated by a logarithm of odds (LOD) score of 17.94 (Fig. 2A to D). The proportion of phenotypic variance $\left(R^{2}\right)$ explained by the QTL was $14.3 \%$ in $2012,18.2 \%$ in 2013 , and $33 \%$ in 2014 , indicating that this QTL was the major contributor to powdery mildew resistance in the field. Although the LOD peak was consistent with resistance expressed as IT, this was not always significant in the greenhouse tests (Fig. 2E). However, the QTL located on chromosome 2AL was the only locus that was found to be associated with powdery mildew resistance at the seedling stage. This QTL was temporarily designated PmHo.

Plant-pathogen interactions. In the light microscopy and CLSM studies, at least 2,000 plant-pathogen interactions were studied. The three pathotypes of B. graminis f. sp. tritici exhibited two different IT following inoculation of Mv Hombár: pathotypes 76 and 51 were avirulent $(\mathrm{IT}=0)$, while 51 -Ho was moderately virulent $($ IT = 3) 1 week after inoculation. Meanwhile, all three pathotypes were found to be virulent $(I T=4)$ on the susceptible controls Ukrainka and Carstens V and avirulent $(\mathrm{IT}=0)$ on Nannong 02Y23 winter wheat and Orca barley, included as resistant controls.

In the case of pathotypes 76 and 51, no significant difference in fungal growth was detected on Mv Hombár and on the susceptible and resistant controls until $24 \mathrm{hpi}$. The conidia formed primary and appressorial germ tubes on all genotypes, including Mv Hombár (Fig. 3A and B). The first penetration and development of haustorium initials in the epidermal cells of the susceptible controls were observed at 24 hpi (Fig. 3C and D). For $50 \%$ of the germinating conidia, the infection hyphae stopped growing at $48 \mathrm{hpi}$ at approximately the penetration stage and died at this stage on Mv Hombár. The remaining conidia formed young colonies following the penetration (Fig. 3E) and formation of a well-developed haustorium with lobes (Fig. 3F), similarly to those observed on the susceptible controls (Fig. 3G and $\mathrm{H}$ ). On Mv Hombár, some of the colonies (approximately 10\%) exhibited several (four to five) secondary penetration sites (Fig. 3I) which also developed haustoria (Fig. 3J) at $72 \mathrm{hpi}$. On the susceptible controls, the rest of the conidia formed young colonies with intensive hyphal growth (Fig. 3K) and numerous secondary haustoria (Fig. 3L), and foot cells of conidiophores occasionally appeared. The first well-developed conidiophores emerged on the susceptible controls at 96 hpi (Fig. 30 and P) and were present in abundance bearing mature conidia at $168 \mathrm{hpi}$, when the symptoms of severe powdery mildew infection were visible to the naked eye. In contrast, colonies on Mv Hombár remained sparse (Fig. 3M and N), and the rest of them died by the end of the experiment. A few colonies formed conidiophores (approximately 1\%) that were observed at 168 hpi. Fungal growth was arrested at the appressorial germ tube stage before penetration in both the resistant and nonhost controls.

Papillae formation was observed in all genotypes at most sites where appressorial germ tubes attempted to penetrate, as well as at the tips of primary germ tubes that reached the leaf surface. However, the general cessation of fungal development was exclusively associated with papilla formation in the nonhost interaction type (Orca barley). In Mv Hombár, almost $75 \%$ of the papillae were penetrated,
$2 \mathrm{~A}$

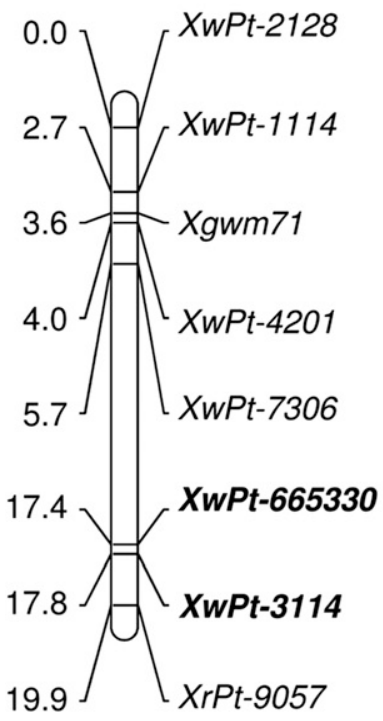

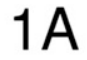

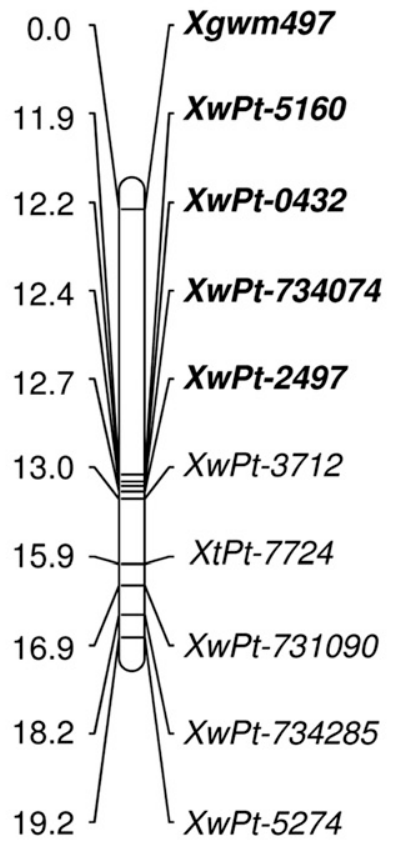

2B

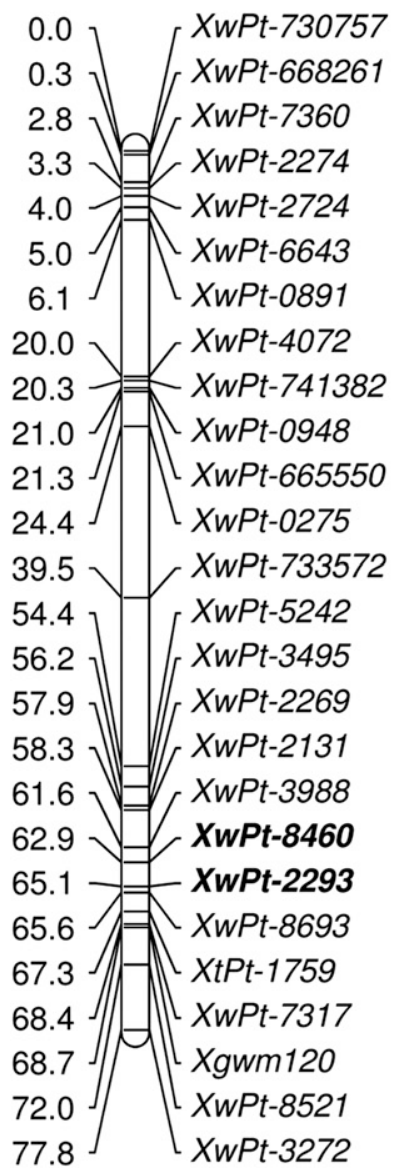

2D

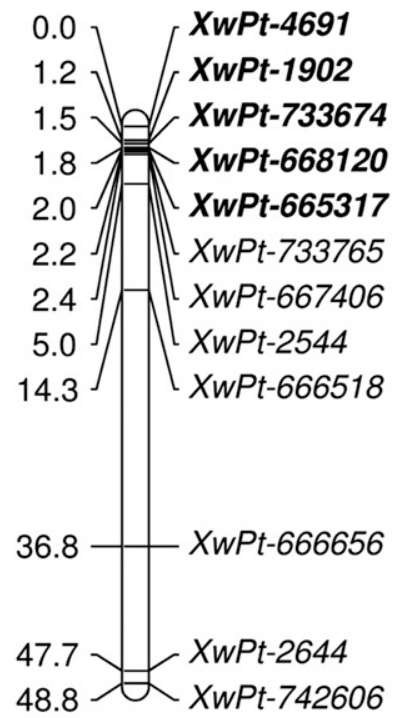

Fig. 1. Genetic linkage maps of the four quantitative trait loci (QTL) that were associated with powdery mildew resistance in Mv Hombár winter wheat and identified based on 435 diversity arrays technology and simple-sequence repeat markers. Marker names are shown on the right side of the maps, and the markers included in QTL are shown in bold. Haldane's map distances (in centimorgans) are shown on the left side of the maps. 
even in the case of interactions where fungal growth ceased at approximately the penetration stage. Posthaustorial HR, detected as the agglutination of cytoplasm, autofluorescence, and aniline blue staining of affected cells, was observed in all genotypes at various frequencies.
Its incidence was significantly more frequent in Mv Hombár and the resistant control Nannong 02Y23 (approximately 70 and 90\%, respectively). $\mathrm{H}_{2} \mathrm{O}_{2}$ accumulation, detected by DAB staining, was observed in all genotypes and was localized in the papillae around the
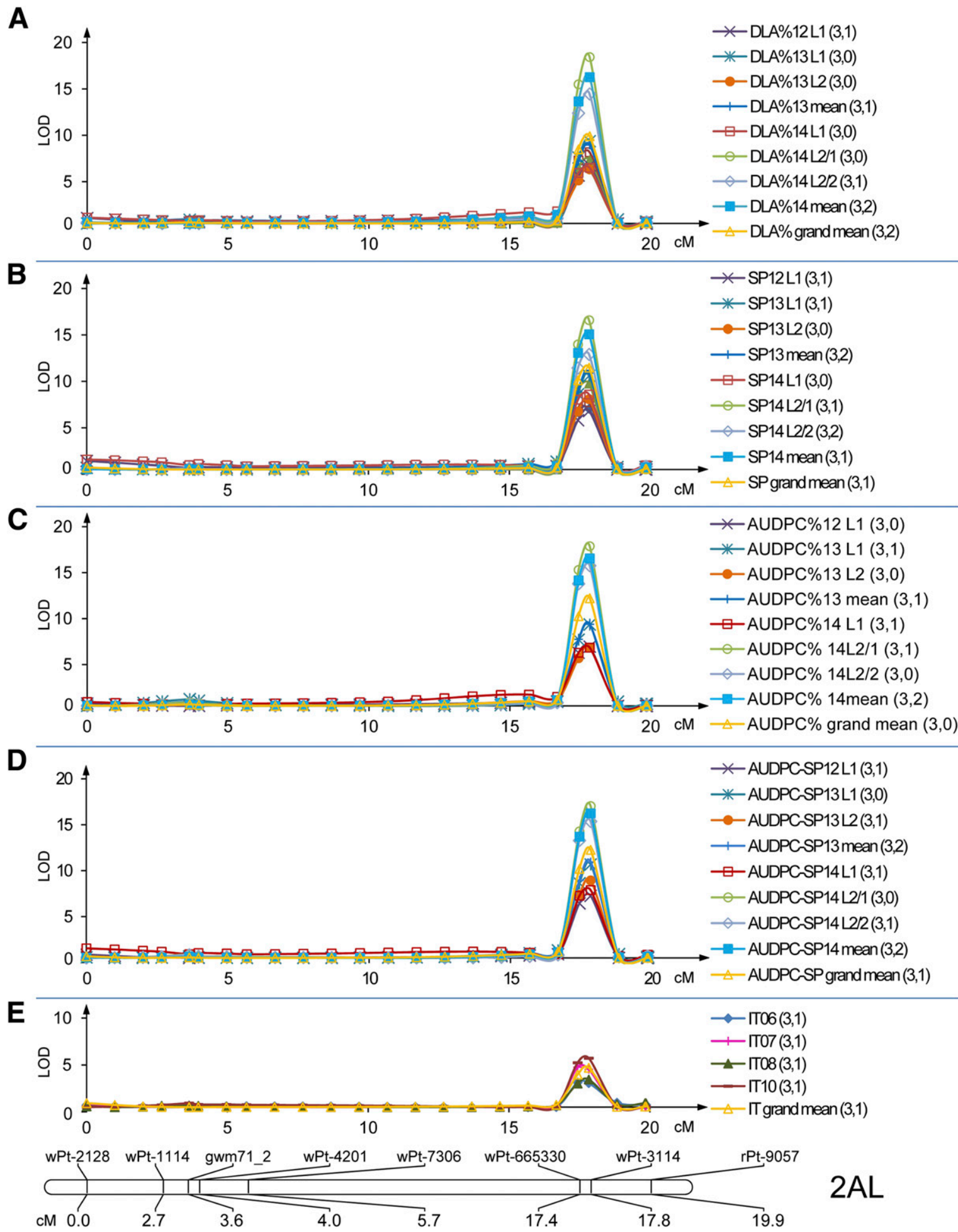

Fig. 2. Logarithm of odds (LOD) peak values of the major effect quantitative trait loci (QTL) for powdery mildew resistance localized on chromosome $2 \mathrm{AL}$ and flanked with diversity arrays technology markers XwPt-3114 and XwPt-665330. LOD peak values were calculated using the multiple QTL model (MQM) procedure, and represent the effect of the QTL on the resistance expressed by A, percentage diseased leaf area at the last scoring date (DLA\%); B, infection level based on the Saari-Prescott scale at the last scoring date (SP); C, area under the disease progress curve (AUDPC) calculated from the percentage diseased leaf area (AUDPC\%); D, AUDPC calculated from the Saari-Prescott data (AUDPC-SP); and $\mathbf{E}$, infection types in the greenhouse seedling test (IT). Designations of the powdery mildew infection datasets include abbreviations of the scoring methods, years, experimental locations with replications (if any), and the threshold of LOD significance $(P=5 \%)$ in parentheses. Numbers $06,07,08,10,12,13$, and 14 stand for the years $2006,2007,2008,2010,2012,2013$, and 2014, respectively. L1 and L2 represent location 1 and location 2, respectively, with L2/1 and L2/2 indicating the two replications at location 2 in 2014. Means and grand means calculated from the datasets obtained from single scoring methods in single years and in all years of the experiment, respectively, are also presented. 
penetration sites and in whole cells attacked by B. graminis f. sp. tritici but its incidence was inconsistent and occurred regardless of the type of interaction and sampling time.

During the routine virulence survey of the local population of B. graminis f. sp. tritici, a new pathotype, the first capable of causing visible symptoms on Mv Hombár, has been identified recently. This new pathotype showed a virulence profile identical to that of pathotype 51 on the modified differential set, and was tentatively designated as 51-Ho in this study. Pathotype 51-Ho was avirulent on the resistant controls and virulent on the susceptible controls.
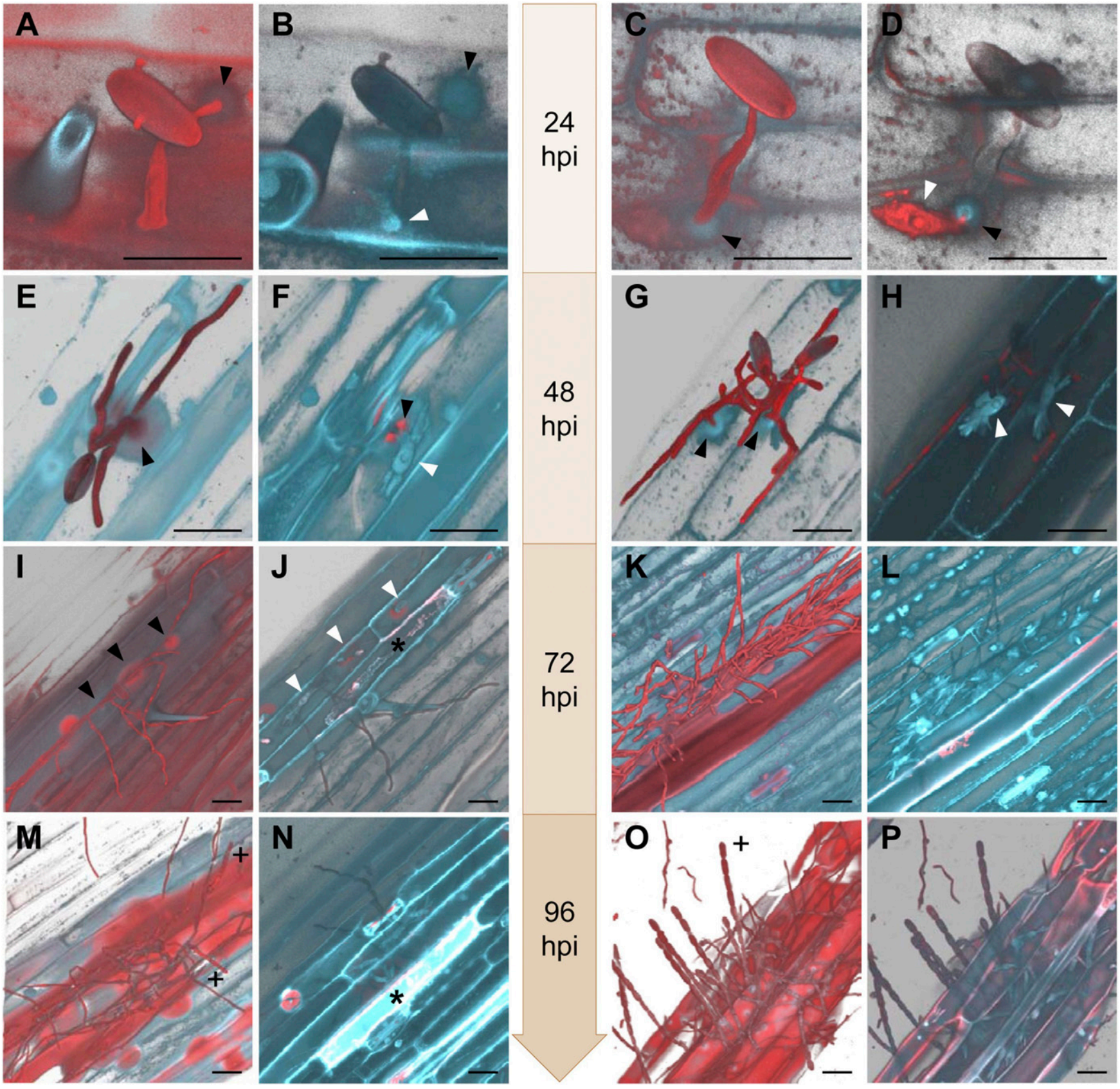

Fig. 3. Three-dimensional reconstructions of plant-pathogen interactions on resistant Mv Hombár winter wheat carrying PmHo following inoculation with pathotype 76 of Blumeria graminis f. sp. tritici compared with those observed on susceptible Ukrainka winter wheat. The time scale in the middle represents the four main sampling dates in hours postinoculation (hpi). Interactions corresponding to each sampling date on A, B, E, F, I, J, M, and N, Mv Hombár are presented on the left side of the time scale and $\mathbf{C}, \mathbf{D}, \mathbf{G}, \mathbf{H}, \mathbf{K}, \mathbf{L}, \mathbf{O}$, and $\mathbf{P}$, Ukrainka on the right side. Interactions are shown in two adjacent pictures from two viewpoints: the leaf surface and the interior of the host epidermal cell. A and $\mathbf{B}$, Conidium with three short primary germ tubes (PGT) and one appressorial germ tube (AGT). A cell wall apposition (papilla) beneath one of the PGT is shown by black arrowheads, and a papilla initial is just emerging opposite the AGT prior to penetration (white arrowhead). $\mathbf{C}$ and $\mathbf{D}$, Conidium with an AGT at the postpenetration stage. A papilla is shown by black arrowheads around the penetration peg, which developed into a haustorium initial (white arrowhead). $\mathbf{E}$ and $\mathbf{F}$, Young colony formed a well-developed haustorium with digitate lobes (white arrowhead) and a papilla at the penetration site (black arrowheads). $\mathbf{G}$ and $\mathbf{H}$, Two young colonies with well-developed haustoria (white arrowheads) and branching extracellular hyphae. Black arrowheads indicate penetrated papillae. I and $\mathbf{J}$, Colony consisting of sparse, thin hyphae with a few branching points and haustoria at different developmental stages (white arrowheads) near the corresponding penetration sites (black arrowheads). The asterisk shows an epidermal cell with agglutination of the cytoplasm. $\mathbf{K}$ and $\mathbf{L}$, Colony consisting of dense branching hyphae that have penetrated into host epidermal cells at many sites, and haustoria at various developmental stages. $\mathbf{M}$ and $\mathbf{N}$, Undeveloped colony bearing two young conidiophores (plus signs) and retarded by an intensive plant defense response, including papilla formation and hypersensitivity reaction (asterisk). $\mathbf{O}$ and $\mathbf{P}$, Sporulating colony with numerous welldeveloped conidiophores (plus sign). In most cases, fungal development on Mv Hombár was arrested at approximately the penetration stage (approximately $50 \%$ ) (A and B) or at the young colony stage (approximately 40\%) (E and F), while conidiophores only developed occasionally (approximately 1\%) (M and N). Scale bar $=50 \mu \mathrm{m}$. 
Microscopic observations on Mv Hombár inoculated with pathotype 51-Ho revealed an infection response pattern involving papillae formation, $\mathrm{H}_{2} \mathrm{O}_{2}$ accumulation, and posthaustorial $\mathrm{HR}$ in penetrated epidermal cells (Fig. 4A), similar to that described in the case of incompatible interactions with pathotypes 76 and 51 (Fig. 4B). Fungal development on Mv Hombár was more profuse than that with pathotypes 76 and 51 (Fig. 4A and B), and the whole asexual cycle, from conidial germination to the formation of mature conidia, was completed. However, significantly fewer sporulating colonies (30 to 40\%) were found on Mv Hombár than on the susceptible controls (Fig. 4C) following inoculation with pathotype 51-Ho. Moreover, a delay in fungal development was observed on this genotype compared with that on the susceptible controls: sporulating powdery mildew colonies on Mv Hombár at 168 hpi were similar to those on the susceptible controls at $96 \mathrm{hpi}$. There were no differences in fungal development between pathotypes 51-Ho, 51, and 76 on the susceptible controls (Fig. 4D).

\section{DISCUSSION}

We identified and characterized a new powdery mildew resistance gene designated as $\mathrm{PmHo}$ in Mv Hombár winter wheat. Genetic mapping localized this gene on the long arm of chromosome $2 \mathrm{~A}$. To date, 12 powdery mildew resistance loci or genes have been mapped on this chromosome arm (McIntosh et al. 2016). A comparison of genetic maps containing Pm50 (Mohler et al. 2013), PmHNK54 (Xu et al. 2011), and PmHo indicated that these three genes map in the same region. Based on the analysis of Mohler et al. (2013), Pm50 was not grouped with markers linked to Pm4d (Schmolke et al. 2012) and was distinct from the Pm4 alleles-namely, Pm4a, Pm4b (The et al. 1979), Pm4c (Hao et al. 2008), and Pm4d (Schmolke et al. 2012) - and from genes PmPS5A (Zhu et al. 2005) and $p m X$ (Fu et al. 2013). Consequently, $\mathrm{PmHo}$ also represents a gene localized independently from the Pm4 alleles, PmPS5A, and $p m X$ on chromosome 2AL. When comparing marker maps of the genes PmHo, Pm50, and PmHNK54 (Fig. 5), based on common markers (XwPt-3114, XwPt-665330, XwPt-7306, $X g w m-372$, and Xbarc5), PmHo is clearly distinguishable from the other two genes earlier localized in this region. Because Mv Matador winter wheat (bred in Martonvásár, Hungary), one of the parents of Mv Hombár, has long been susceptible to powdery mildew in Hungary, PmHo must have originated from the other parent, Fleming (bred in Georgia, United States), which showed field resistance in Hungary.

The segregation ratio and the consistent effect in all environments (expressed by the LOD scores) (Fig. 2; Supplementary Table S1) indicate that $\mathrm{PmHo}$ is a major dominant powdery mildew resistance gene. The major effect of PmHo was also supported by the racespecific nature of resistance in Mv Hombár. This was shown by the emergence of a new moderately virulent pathotype, designated here as 51-Ho, that was, to some extent, able to infect Mv Hombár, developing visible symptoms with sporulating colonies. Among approximately 300 single-colony isolates tested in Hungary in the last decade and 10 additional isolates tested in China, no other virulent isolate was found on this cultivar (G. Vida, unpublished data).

Posthaustorial HR in response to powdery mildew pathogens is often associated with race-specific host resistance (Gill et al. 2015; Jørgensen 1994). The plant defense response of Mv Hombár following inoculation with $B$. graminis f. sp. tritici pathotypes 76 and 51 was manifested at various stages of fungal development. The present results showed that, at the cellular level, posthaustorial HR was the most important but not the exclusive plant defense response in Mv Hombár. Penetration was successful in $70 \%$ of the interactions and, in these cases, posthaustorial HR was prevalently involved in resistance. Accordingly, fungal growth was mostly arrested during haustorium formation (the stage considered to be an indicator of successful establishment) or in the early stages of colony development. Although the accumulation of $\mathrm{H}_{2} \mathrm{O}_{2}$ is believed to be a biochemical marker distinguishing
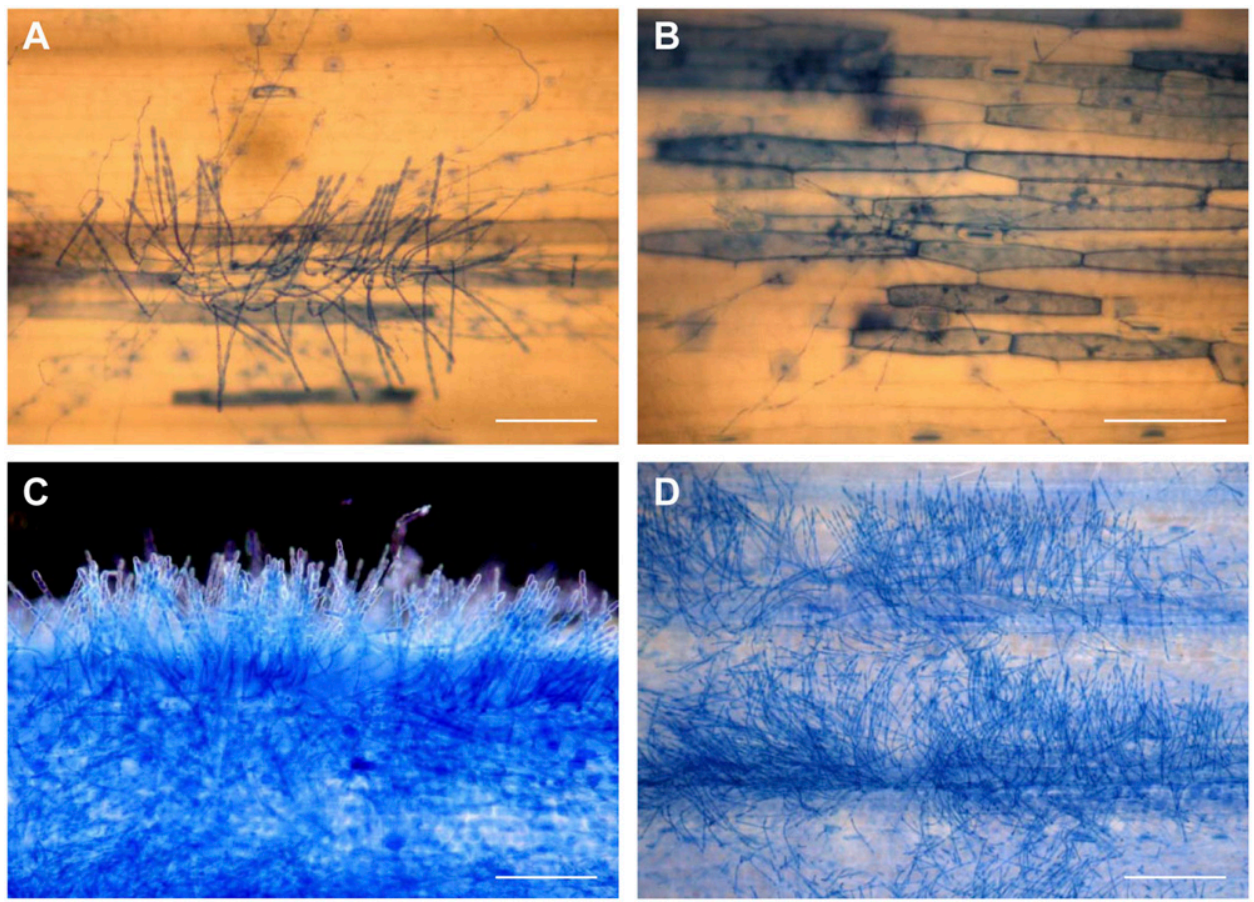

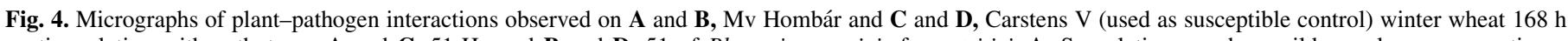

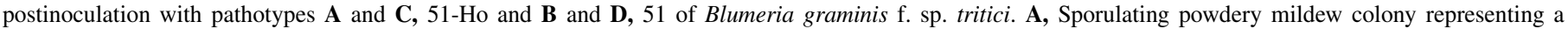

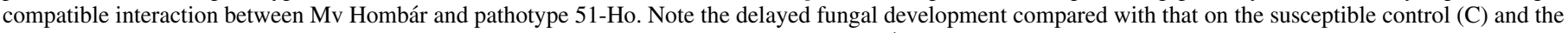

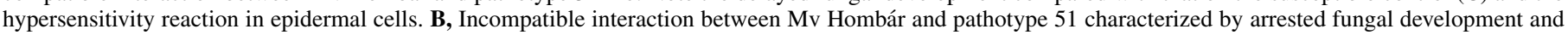

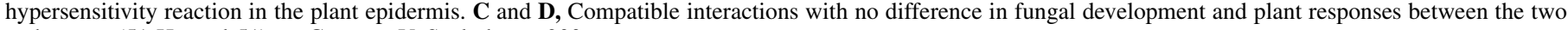
pathotypes (51-Ho and 51) on Carstens V. Scale bar $=200 \mu \mathrm{m}$. 
between penetrated and nonpenetrated cells in the interactions of barley and wheat with the powdery mildew fungus (Hückelhoven et al. 1999; $\mathrm{Li}$ et al. 2005; Trujillo et al. 2004b), $\mathrm{H}_{2} \mathrm{O}_{2}$ accumulation detected by DAB staining was inconsistent in this study, similar to the results published by Troch et al. (2014).

In $30 \%$ of the interactions, penetration was prevented by papillae. This is not surprising, given that papilla formation occurs in both race-specific and nonrace-specific incompatible interactions as well as in compatible ones (Zeyen et al. 2002). However, Troch et al. (2014) provided evidence that effective papillae in triticale were the most important barriers to infection with a recently adapted form of the powdery mildew pathogen $B$. graminis, which has expanded its host range from wheat to triticale (Troch et al. 2012; Walker et al. 2011). Moreover, Ellinger et al. (2013) proved that callose deposition in the papillae may play an active role in the resistance of Arabidopsis to an adapted powdery mildew pathogen. Troch et al. (2014) and Ellinger et al. (2013) pointed out that the formation of effective papillae may be of relevance in host resistance. In Mv Hombár, the formation of effective papillae in $30 \%$ of interactions may lead to similar conclusions. The present and abovementioned studies, together with those concluding that posthaustorial HR may contribute effectively to the nonhost resistance in rice infected with the wheat powdery mildew fungus (Cheng et al. 2015), underline that host and nonhost resistance, despite their classification into two classes, share more similarities than differences in their mechanism and resistance processes (Gill et al. 2015), which are also reflected at the cellular level.
The plant defense response to adapted $B$. graminis isolates was observed in cereals as a cell-autonomous phenomenon, meaning that similar neighboring epidermal cells showed differing success in preventing fungal penetration from an appressorial germ tube and subsequent haustorium formation (establishment) in intact host cells (Hückelhoven 2014). Similar patterns were observed in Mv Hombár following inoculation with the only virulent pathotype, 51-Ho. In addition, the extent of the delay in fungal growth differed even within the same leaf segment, which affected the completion of the asexual life cycle, leading to the development of fewer, smaller colonies compared with the susceptible control. The delay in the development of $B$. graminis f. sp. tritici isolates from triticale on common wheat was explained by unknown mechanisms other than HR (Troch et al. 2014). In contrast, delayed fungal growth was accompanied by posthaustorial HR in interactions between the pathotype 51-Ho and Mv Hombár. Although this pathotype was, to some extent, able to infect $\mathrm{Mv}$ Hombár and, most probably, overcame the resistance conferred by $\mathrm{PmHo}$, other loci might also be involved in the resistance of this cultivar. This was shown by the delayed development of the pathotype 51-Ho and could be explained by the potential effect of any of the QTL identified on chromosomes 1A, 2B, and 2D, which were found to exhibit minor effects associated with powdery mildew resistance in Mv Hombár. No indication of identities of these minor QTL was found with those reported previously in association with powdery mildew resistance in wheat ( $\mathrm{Li}$ et al. 2014; McIntosh et al. 2016).

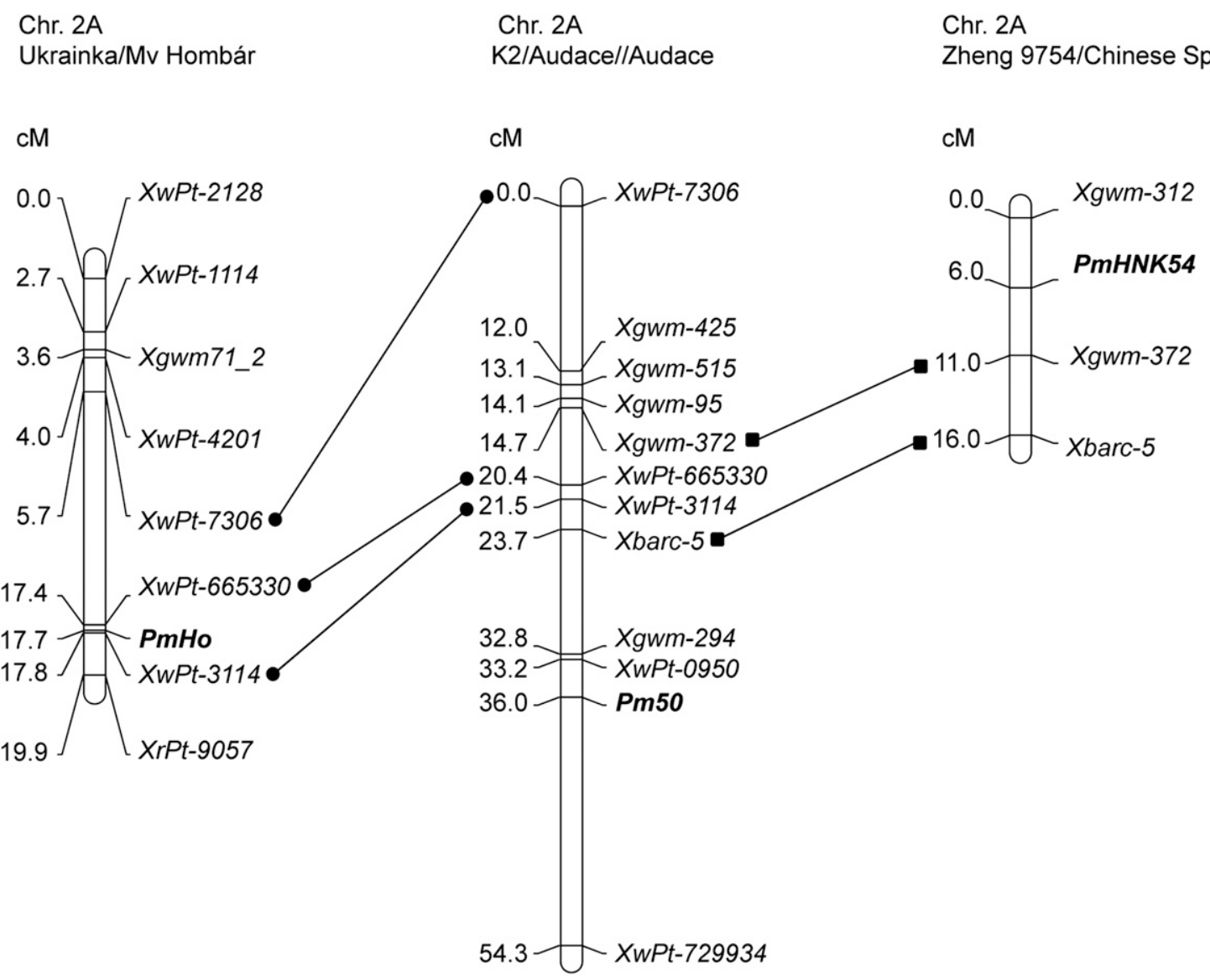

Fig. 5. Comparative partial linkage maps of chromosome 2A including powdery mildew resistance genes PmHo, Pm50 (Mohler et al. 2013 ), and PmHNK54 (Xu et al. 2011) identified in the populations Ukrainka/Mv Hombár, K2/Audace//Audace, and Zheng 9754/Chinese Spring, respectively. Resistance genes (highlighted in bold) and marker names are shown on the right side of the maps, and the map positions (in centimorgans) are shown on the left side. Common markers between linkage maps of PmHo and Pm50 are connected by solid lines with circles, while those of Pm50 and PmHNK54 are connected by solid lines with squares. 


\section{ACKNOWLEDGMENTS}

We thank R. A. McIntosh for valuable comments on the manuscript. This work was supported by the bilateral Hungarian-Chinese science and technology program (TÉT $12 \mathrm{CN}-1-2012-0004$ ) and by the Chinese Hi-Tech program (2012AA101105). T. Jankovics's contribution to this study was partly supported by a grant from the Hungarian Scientific Research Fund (OTKA PD 112468) and by a János Bolyai Research Scholarship of the Hungarian Academy of Sciences (MTA). The acquisition of the Leica SP8 confocal laser-scanning microscope was funded by a Research Infrastructure Grant from the MTA (GENPROF IF-18/2012).

\section{LITERATURE CITED}

Akbari, M., Wenzl, P., Caig, V., Carling, J., Xia, L., Yang, S., Uszynski, G., Mohler, V., Lehmensiek, A., Kuchel, H., Hayden, M. J., Howes, N., Sharp, P., Vaughan, P., Rathmell, B., Huttner, E., and Kilian, A. 2006. Diversity arrays technology (DArT) for high-throughput profiling of the hexaploid wheat genome. Theor. Appl. Genet. 113:1409-1420.

Bennett, F. G. A. 1984. Resistance to powdery mildew in wheat: A review of its use in agriculture and breeding programs. Plant Pathol. 33:279-300.

Brown, J. K. M., and Hovmøller, M. S. 2002. Aerial dispersal of fungi on the global and continental scales and its consequences for plant disease. Science 297:537-541.

Chakravarti, I. M., Laha, R. G., and Roy, J. 1967. Handbook of Methods of Applied Statistics, Vol. I. John Wiley and Sons, New York.

Cheng, Y., Yao, J., Zhang, H., Huang, L., and Kang, Z. 2015. Cytological and molecular analysis of nonhost resistance in rice to wheat powdery mildew and leaf rust pathogens. Protoplasma 252:1167-1179.

Cowger, C., Miranda, L., Griffey, C., Hall, M., Murphy, J. P., and Maxwell, J. 2012. Wheat powdery mildew. Pages 84-119 in: Disease Resistance in Wheat. I. Sharma, ed. CABI International, Oxfordshire, UK.

Dean, R., Van Kan, J. A. L., Pretorius, Z. A., Hammond-Kosack, K. E., Di Pietro, A., Spanu, P. D., Rudd, J. J., Dickman, M., Kahmann, R., Ellis, J., and Foster, G. D. 2012. The top 10 fungal pathogens in molecular plant pathology. Mol. Plant Pathol. 13:414-430.

Eichmann, R., and Hückelhoven, R. 2008. Accommodation of powdery mildew fungi in intact plant cells. J. Plant Physiol. 165:5-18.

Ellinger, D., Naumann, M., Falter, C., Zwikowics, C., Jamrow, T., Manisseri, C., Somerville, S. C., and Voigt, C. A. 2013. Elevated early callose deposition results in complete penetration resistance to powdery mildew in Arabidopsis. Plant Physiol. 161:1433-1444.

Flor, H. H. 1971. Current status of the gene-for-gene concept. Annu. Rev. Phytopathol. 9:275-296.

Fu, B., Chen, Y., Li, N., Ma, H., Kong, Z., Zhang, L., Jia, H., and Ma, Z. 2013. pmX: A recessive powdery mildew resistance gene at the Pm4 locus identified in wheat landrace Xiaohongpi. Theor. Appl. Genet. 126:913-921.

Gill, U. S., Lee, S., and Mysore, K. S. 2015. Host versus nonhost resistance: Distinct wars with similar arsenals. Phytopathology 105:580-587.

Hao, C., Chen, Y., Zhang, B., Li, Y., Zuo, H., Qi, T., and Ma, Q. 2013. Histochemical comparison of the nonhost tomato with resistant wheat against Blumeria graminis f. sp. tritici. Microsc. Res. Tech. 76:514-522.

Hao, Y., Liu, A., Wang, Y., Feng, D., Gao, J., Li, X., Liu, S., and Wang, H. 2008. Pm23: A new allele of Pm4 located on chromosome 2AL in wheat. Theor. Appl. Genet. 117:1205-1212.

Hückelhoven, R. 2014. The effective papilla hypothesis. New Phytol. 204:438-440.

Hückelhoven, R., Dechert, C., and Kogel, K. H. 2001. Non-host resistance of barley is associated with a hydrogen peroxide burst at sites of attempted penetration by wheat powdery mildew fungus. Mol. Plant Pathol. 4:487-500.

Hückelhoven, R., Fodor, J., Preis, C., and Kogel, K. H. 1999. Hypersensitive cell death and papilla formation in barley attacked by powdery mildew fungus are associated with hydrogen peroxide but not with salicylic acid accumulation. Plant Physiol. 119:1251-1260.

Hückelhoven, R., and Panstruga, R. 2011. Cell biology of the plant-powdery mildew interaction. Curr. Opin. Plant Biol. 14:738-746.

Jankovics, T., Komáromi, J., Fábián, A., Jäger, K., Vida, G., and Kiss, L. 2015. New insights into the life cycle of the wheat powdery mildew: Direct observation of ascosporic infection in Blumeria graminis f. sp. tritici. Phytopathology 105:797-804.

Jørgensen, J. H. 1994. Genetics of powdery mildew resistance in barley. Crit. Rev. Plant Sci. 13:97-119.

Komáromi, J., and Vida, G. 2009. Effectiveness of designated major powdery mildew resistance genes in various wheat genotypes. Cereal Res. Commun. 37:213-216.

Komáromi, J., Zhang, Z., De Pace, C., Veisz, O., and Vida, G. 2014. Dasypyrum villosum eredetü lisztharmat-rezisztencia beépítése martonvásári búzafajtákba markerszelekcióval (Transfer of powdery mildew resistance originating from Dasypyrum villosum into the winter wheat cultivars bred in Martonvásár.) In: Veisz $\mathrm{O}$ (ed) Növénynemesítés a megújuló mezőgazdaságban: XX Növénynemesítési Tudományos Nap. (Plant breeding in the renewing agriculture: 20th Scientific Day of Plant Breeding), Budapest, Hungary, Hungarian Academy of Sciences Proceedings. Pages 249-253.

Kruskal, W. H., and Wallis, W. A. 1952. Use of ranks in one-criterion variance analysis. J. Am. Stat. Assoc. 47:583-621.

Li, A. L., Wang, M. L., Zhou, R. H., Kong, X. Y., Huo, N. X., Wang, W. S., and Jia, J. Z. 2005. Comparative analysis of early $\mathrm{H}_{2} \mathrm{O}_{2}$ accumulation in compatible and incompatible wheat-powdery mildew interactions. Plant Pathol. 54:308-316.

Li, C., Faino, L., Dong, L., Fan, J., Kiss, L., de Giovanni, C., Lebeda, A., Scott, J., Matsuda, Y., Toyoda, H., Lindhout, P., Visser, R. G. F., Bonnema, G., and Bai, Y. 2012. Characterization of polygenic resistance to powdery mildew in tomato at cytological, biochemical and gene expression level. Mol. Plant Pathol. 13:148-159.

Li, Z., Lan, C., He, Z., Singh, R. P., Rosewarne, G. M., Chen, X., and Xia, X. 2014. Overview and application of QTL for adult plant resistance to leaf rust and powdery mildew in wheat. Crop Sci. 54:1907-1925.

Mann, H. B., and Whitney, D. R. 1947. On a test of whether one of two random variables is stochastically larger than the other. Ann. Math. Stat. 18:50-60

McIntosh, R. A., Dubcovsky, J., Rogers, W. J., Morris, C., Appels, R., and Xia, X. C. 2016. Catalogue of gene symbols for wheat. Online publication. KomugiWheat Genetic Resources Database. http://shigen.nig.ac.jp/wheat/komugi/

Mohler, V., Bauer, C., Schweizer, G., Kempf, H., and Hartl, L. 2013. Pm50: A new powdery mildew resistance gene in common wheat derived from cultivated emmer. J. Appl. Genet. 54:259-263.

Niks, R. E., and Marcel, T. C. 2009. Non-host and basal resistance: How to explain specificity? New Phytol. 182:817-828.

Nover, I. 1958. Sechsjährige Beobachtungen über die physiologische Spezialisierung des echten Mehltaus (Erysiphe graminis DC.) von Weizen und Gerste in Deutschland. Phytopathol. Z. 31:85-107.

Röder, M. S., Korzun, V., Wendehake, K., Plaschke, J., Tixier, M., Leroy, P., and Ganal, M. W. 1998. A microsatellite map of wheat. Genetics 149: 2007-2023.

Saari, E. E., and Prescott, J. M. 1975. A scale for appraising the foliar intensity of wheat diseases. Plant Dis. Rep. 59:377-380.

Schmolke, M., Mohler, V., Hartl, L., Zeller, F. J., and Hsam, S. L. K. 2012. A new powdery mildew resistance allele at the $P m 4$ wheat locus transferred from einkorn (Triticum monococcum). Mol. Breed. 29:449-456.

Schulze-Lefert, P., and Panstruga, R. 2011. A molecular evolutionary concept connecting nonhost resistance, pathogen host range, and pathogen speciation. Trends Plant Sci. 16:117-125.

Shapiro, S. S., and Wilk, M. B. 1965. An analysis of variance test for normality (complete samples). Biometrika 52:591-611.

Szunics, L., and Szunics, Lu. 1984. A study of the physiological specialization of the powdery mildew of wheat (1970/71-1982/83). Novenytermeles 33: 507-514. (In Hungarian)

The, T. T., McIntosh, R. A., and Bennett, F. G. A. 1979. Cytogenetical studies in wheat. IX. Monosomic analysis, telocentric mapping and linkage relationships of genes Sr21, Pm4 and Mle. Aust. J. Biol. Sci. 32:115-125.

Thordal-Christensen, H. 2003. Fresh insights into processes of nonhost resistance. Curr. Opin. Plant Biol. 6:351-357.

Thordal-Christensen, H., Zhang, Z., Wei, Y., and Collinge, D. B. 1997. Subcellular localization of $\mathrm{H}_{2} \mathrm{O}_{2}$ in plants: $\mathrm{H}_{2} \mathrm{O}_{2}$ accumulation in papillae and hypersensitive response during the barley powdery mildew interaction. Plant J. 11:1187-1194.

Troch, V., Audenaert, K., Bekaert, B., Höfte, M., and Haesaert, G. 2012. Phylogeography and virulence structure of the powdery mildew population on its 'new' host triticale. BMC Evol. Biol. 12:76.

Troch, V., Audenaert, K., Vanheule, A., Bekaert, B., Höfte, M., and Haesaert, G. 2014. The importance of non-penetrated papillae formation in the resistance response of triticale to powdery mildew (Blumeria graminis). Plant Pathol. 63:129-139.

Trujillo, M., Kogel, K. H., and Hückelhoven, R. 2004a. Superoxide and hydrogen peroxide play different roles in the nonhost interaction of barley and wheat with inappropriate formae speciales of Blumeria graminis. Mol. Plant-Microbe Interact. 17:304-312.

Trujillo, M., Troeger, M., Niks, R. E., Kogel, K. H., and Hückelhoven, R. 2004b. Mechanistic and genetic overlap of barley host and non-host resistance to Blumeria graminis. Mol. Plant Pathol. 5:389-396.

Walker, A. S., Bouguennec, A., Confais, J., Morgant, G., and Leroux, P. 2011. Evidence of host-range expansion from new powdery mildew (Blumeria graminis) infections of triticale ( $\times$ Triticosecale) in France. Plant Pathol. 60:207-220.

Xu, W., Li, C., Hu, L., Wang, H., Dong, H., Zhang, J., and Zan, X. 2011. Identification and molecular mapping of PmHNK54: A novel powdery mildew resistance gene in common wheat. Plant Breed. 130:603-607.

Zeyen, R. J., Carver, T. L. W., and Lyngkjaer, M. F. 2002. Epidermal cell papillae. Pages 107-125 in: The Powdery Mildews. A Comprehensive Treatise. R. R. Bélanger, W. R. Bushnell, A. J. Dik, and T. L. W. Carver, eds. American Phytopathological Society, St. Paul, MN.

Zhu, Z., Zhou, R., Kong, X., Dong, Y., and Jia, J. 2005. Microsatellite markers linked to 2 powdery mildew resistance genes introgressed from Triticum carthlicum accession PS5 into common wheat. Genome 48:585-590. 